\title{
Rational modification of substrate binding site by structure-based engineering of a cellobiose 2-epimerase in Caldicellulosiruptor saccharolyticus
}

\author{
Ah-Reum Park, Jin-Sook Kim, Seung-Won Jang, Young-Gyun Park, Bong-Seong Koo and Hyeon-Cheol Lee* (i)
}

\begin{abstract}
Background: Lactulose, a synthetic disaccharide, has received increasing interest due to its role as a prebiotic, specifically proliferating Bifidobacilli and Lactobacilli and enhancing absorption of calcium and magnesium. The use of cellobiose 2-epimerase (CE) is considered an interesting alternative for industrial production of lactulose. CE reversibly converts D-glucose residues into D-mannose residues at the reducing end of unmodified $\beta$-1,4-linked oligosaccharides, including $\beta-1,4-$ mannobiose, cellobiose, and lactose. Recently, a few CE 3D structure were reported, revealing mechanistic details. Using this information, we redesigned the substrate binding site of CE to extend its activity from epimerization to isomerization.

Results: Using superimposition with 3 known CE structure models, we identified 2 residues (Tyr114, Asn184) that appeared to play an important role in binding epilactose. We modified these residues, which interact with $\mathrm{C} 2$ of the mannose moiety, to prevent epimerization to epilactose. We found a Y114E mutation led to increased release of a byproduct, lactulose, at $65^{\circ} \mathrm{C}$, while its activity was low at $37^{\circ} \mathrm{C}$. Notably, this phenomenon was observed only at high temperature and more reliably when the substrate was increased. Using Y114E, isomerization of lactose to lactulose was investigated under optimized conditions, resulting in $86.9 \mathrm{~g} / \mathrm{l}$ of lactulose and $4.6 \mathrm{~g} / \mathrm{l}$ of epilactose for $2 \mathrm{~h}$ when $200 \mathrm{~g} / \mathrm{l}$ of lactose was used.

Conclusion: These results showed that the Y114E mutation increased isomerization of lactose, while decreasing the epimerization of lactose. Thus, a subtle modification of the active site pocket could extend its native activity from epimerization to isomerization without significantly impairing substrate binding. While additional studies are required to scale this to an industrial process, we demonstrated the potential of engineering this enzyme based on structural analysis.
\end{abstract}

Keywords: Lactulose, Cellobiose 2-epimerase, Lactose, Structure analysis, Protein engineering

\section{Background}

Recently, multiple cellobiose 2-epimerases (CE: EC 5.1.3.11) were reported for industrial process applications using lactose [1-4]. Specifically, CE converts lactose into the rare sugars, lactulose and epilactose (4-O- $\beta$ D-galactosyl-D-mannose), which are useful for medical

*Correspondence: hclee0609@gmail.com

ForBioKorea Co., Ltd., Gasan digital 2-ro, Geumcheon-gu, Seoul,

Republic of Korea applications as prebiotic agents [5-7]. Lactulose is a synthetic ketose disaccharide that is widely applied in the pharmaceutical and nutraceutical fields, due to its beneficial effects. Lactulose can be used as a gentle laxative for the treatment of constipation and hyper-ammonemia by stimulating growth of beneficial intestinal bifidobacteria but not inducing the proliferation of harmful bacteria belonging to classes Clostridia or Bacteroidetes [5, 7-9].

While there are current efforts to produce lactulose via enzymatic isomerization using CE [3, 4, 9-11], 
drawbacks exist, such as poor substrate solubility and low conversion yield, which need to be improved for industrial applications. It is well known that the substrate (lactose) has relatively low solubility (approx. $225 \mathrm{~g} / \mathrm{l}$ at $37^{\circ} \mathrm{C}$ ) and most CEs partially change their isomerization/ epimerization ratio at high temperature due to accelerating reaction velocity. Recently, CE from Caldicellulosiruptor saccharolyticus (CsCE) was reported as a useful enzyme having higher thermostability than other CEs $[3,12,13]$. Using this CsCE, we screened error-prone PCR-generated enzyme variants to identify those with increased thermostability compared to wild type CsCE [14]. Using a thermostable enzyme, the accelerated reaction at high temperature could have great advantages in producing lactulose, as lactulose is a byproduct produced during epimerization from lactose to epilactose, depending on equilibrium concentrations of lactose and epilactose $[13,15,16]$.

CE was first identified in the ruminal anaerobic bacterium, Ruminococcus albus $[17,18]$, which catalyzes conversion of the glucose residue into a mannose residue or a fructose residue at the reducing end of $\beta$-1,4-linked oligosaccharides, including $\beta$-1,4-mannobiose, cellobiose, and lactose. Epimerases acting on carbohydrates and their derivatives can be divided into 25 groups (EC 5.1.3.) depending on their catalytic reactions and substrate specificities $[19,20]$. While most epimerases, converting the configuration of non-anomeric hydroxyl groups, act on modified active substrates harboring phosphate groups or nucleotide diphosphate groups, CE catalyzes the epimerization of unmodified sugars at the $\mathrm{C} 2$ position. The crystal structures of CE from $R$. albus (RaCE [19]) and Rhodothermus marinus (RmCE [20]) were released recently. The crystal structures confirmed the structure proposed previously by Ito et al. $[18,21]$. The basic conformation of CE consists of $12 \alpha$-helices arranged in an $(\alpha / \alpha)_{6}$ barrel structure (Additional file 1: Figure S1). The handful of known CE sources (e.g. RaCE and RmCE) follow a similar epimerization mechanism and their structures adopt an $(\alpha / \alpha)_{6}$ barrel structure similar to the catalytic domains of $\mathrm{N}$-acetylglucosamine 2-epimerase (AGE) and aldose-ketose isomerase (YihS) [20]. CsCE is also predicted to follow the same epimerization mechanism, because it has an $(\alpha / \alpha)_{6}$ barrel structure similar to the catalytic domains of other CEs and belongs to the AGE superfamily along with AGE and YihS.

In CEs, the active site, with its triple histidine center, is located inside the barrel [19]. Two essential histidine residues, corresponding to the general acid/base catalysts of AGEs, and a third histidine residue located at the bottom of the substrate binding site are required for catalysis. The two essential histidine residues corresponding to CsCE-His247 and CsCE-His377 are completely conserved in CE enzymes, supporting the importance of these residues $[19,20]$. In contrast, the function of the third histidine in CE (RaCE-His184 and CsCE-His188), conserved in known CEs and YihS, was revealed recently $[19,20]$. Many reports proposed that the third histidine residue and its neighbors affect deprotonation of the $\mathrm{C} 2$ atom by interacting with the $\mathrm{O} 2$ atom of reducing end sugars for formation of the cis-enediol intermediate [1922]. Insight from these structural studies and proposed catalytic mechanism inspired us to improve the biological activity for production of lactulose. In an effort to find residues of $\mathrm{CsCE}$ that might improve biological activity, we turned our attention to neighboring residues, such as Tyr114 and Asn184, excluding His residues which play a role as a general acid/base important in stabilizing product binding.

Here, in order to enhance lactulose production from a high concentration of lactose at high temperature, we rationally engineered the binding site of a thermostable CsCE, which was identified in a previous screen, based on its structure [14]. Our hypothesis was that modification of residues involved in interacting with the mannose moiety of epilactose could change epimerization activity to isomerization activity toward lactulose production by inhibiting the conversion from the cis-enediol intermediate to epilactose. In other words, since lactulose is an isomerizing byproduct formed in the reaction epimerizing lactose to epilactose, we hypothesized that an isomerization from lactose to lactulose could be induced by increasing the reaction rate with higher temperature, while delaying the conversion of the cis-enediol intermediate into epilactose. To test this notion, the threedimensional structure of $\mathrm{CsCE}$ was superimposed on the crystal structures of the CEs from $R$. albus (RaCE) and $R$. marinus (RmCE) with epilactose and lactulose analogues $[19,20]$, yielding targeted residues for site-directed mutagenesis to create mutant enzymes with modified substrate binding residues. Comparison of product yields with the mutant enzymes supported our hypothesis. This structure-based approach for converting enzyme properties from epimerization to isomerization is one example of the utility of protein engineering approaches to satisfy industrial needs for enzymatic process, especially using those involving isomerizing and epimerizing enzymes.

\section{Methods \\ Materials}

The restriction endonucleases NheI and EcoRI, T4 DNA ligase, and EX taq polymerase were obtained from Takara (Kyoto, Japan). The expression vector pET28a $(+)$ was obtained from Novagen (Darmstadt, Germany). Plasmid DNA was purified by using DNA mini-preparation kits (Qiagen, Hilden, Germany). Escherichia coli BL21 (DE3) 
(New England Biolabs, Hertfordshire, UK) was used for protein expression. C. saccharolyticus DSM 8903 cell was purchased from DSMZ (Braunschweig, Germany). Standard sugars (lactose, epilactose, and lactulose) for high-performance liquid chromatography (HPLC) were purchased from Sigma-Aldrich (MO, USA).

\section{Gene cloning and expression of cellobiose 2-epimerase}

The genomic DNA from C. saccharolyticus was extracted using the genomic DNA extraction kit (Qiagen, Hilden, Germany). The gene (1173 bp) encoding putative $N$-acylD-glucosamine 2-epimerase (Genebank Accession No. ABP65941) was amplified by PCR using C. saccharolyticus genomic DNA as a template with the following primers. The sequences of forward and reverse primers were 5'-GCT AGC ATG GAT ATT ACA AGG TTT AAG GAA GAT TTA AAA G-3' ${ }^{\prime}$ and $5^{\prime}$-GAA TTC TTA GTC AAC CCT TTT TAT TAT CTC CAA ACA CAT TC-3', respectively. The PCR product was cloned into pET28a $(+)$ vector using NheI and EcoRI restriction sites. The gene was designed at the $5^{\prime}$ end, encoding a short histidine tag and thrombin site. About $50 \mathrm{ng}$ of recombinant pET28a-CSCE plasmid DNA was transformed into E. coli BL21 (DE3) cells using the heat shock method, and transformants were selected on LB agar plate supplemented with kanamycin. DNA sequencing was conducted at the Macrogen facility (Seoul, Korea). The recombinant E. coli cells for protein expression were cultivated with shaking at $200 \mathrm{rpm}, 37^{\circ} \mathrm{C}$ with $30 \mu \mathrm{g} / \mathrm{ml}$ kanamycin until the $\mathrm{OD}_{600}$ reached 0.6. IPTG was added to the culture medium at $0.5 \mathrm{mM}$ to induce enzyme expression and the culture was incubated at $16^{\circ} \mathrm{C}$ for $16 \mathrm{~h}$.

\section{Site-directed mutagenesis}

Site-directed mutagenesis of $\mathrm{CsCE}$ was performed using the QuikChange site-directed mutagenesis kit (Agilent Technologies, CA, USA). Each desired amino acid replacement was generated by using two synthetic oligonucleotide primers. After 16 amplification cycles $\left(95^{\circ} \mathrm{C}\right.$ for $30 \mathrm{~s}, 55^{\circ} \mathrm{C}$ for $1 \mathrm{~min}$, and $68{ }^{\circ} \mathrm{C}$ for $7 \mathrm{~min}$ ) with $P f u$ Turbo DNA polymerase (Agilent Technologies, California, USA), the PCR products were treated with $1 \mathrm{U} D p n \mathrm{I}$, and then the nicked plasmid DNA with the desired mutation was transformed into competent cells of $E$. coli BL21 (DE3). The sequences of all variable mutants were confirmed by DNA sequencing.

\section{Purification of cellobiose 2-epimerase variants}

The grown cells were harvested and disrupted using an ultra sonicator, on ice for $2 \mathrm{~min}$ in a $50 \mathrm{mM}$ PIPES buffer ( $\mathrm{pH}$ 7.5). The unbroken cells and cell debris were removed by centrifugation and $E$. coli proteins were removed by heat treatment as described previously [23].
The samples thus obtained were further purified by Histagged affinity chromatography (HisTrap ${ }^{\mathrm{TM}}$, Amersham Biosciences). The fractions containing the target proteins were collected and dialyzed against $50 \mathrm{mM}$ PIPES buffer $(\mathrm{pH}$ 7.5). The protein concentration was determined by the Lowry method with bovine serum albumin as a standard and homogeneity of the target proteins was assessed by SDS-PAGE.

\section{Lactose conversion assay}

The composition of the reaction mixture in a total volume of $100 \mu \mathrm{l}$ containing $50 \mathrm{mM}$ PIPES buffer ( $\mathrm{pH} 7.5$ ), $20-200 \mathrm{~g} / \mathrm{l}$ of lactose, and $50 \mu \mathrm{g}$ of enzyme was routinely incubated at each tested temperature for defined lengths of time. The rates of formation of lactulose or epilactose from lactose were measured HPLC system with HILICpak VG-50 4E column (Shodex, Kawasaki, Japan). The reaction was stopped by the addition of $\mathrm{HCl}$ to the reaction mixture at a final concentration of $200 \mathrm{mM}$. The concentrations of lactulose, lactose, and epilactose in the resulting solutions were determined by Alliance 2690 HPLC system equipped with a Waters 2410 refractive index (RI) (Waters, Milford, USA) and a HILICpak VG-50 4E column. The column was eluted at $42{ }^{\circ} \mathrm{C}$ with $75 \%$ acetonitrile, $20 \%$ methanol, and $5 \%$ distilled water at a flow rate of $1 \mathrm{ml} / \mathrm{min}$.

\section{Structure determination and refinement}

Structural models of the CEs were obtained from the Protein Data Bank. The known crystal structures CEs (CsCE: PDB ID 4Z4L, RmCE: PDB ID 3WKF, 3WKG, 3WKH, 3WKI, and RaCE: PDB ID 3VW5) were aligned using tools in PyMOL software (https://www.pymol. org/). The structures of CsCE and ligand-bound CsCE were determined by the molecular replacement method with the program AutoMR in the Phenix program package [24] (Additional file 1: Table S1). The structure of apo-CsCE was solved using the structure of RmCE (PDB ID 3 WKF) as a search model. Subsequently, ligandbound $\mathrm{CsCE}$ was determined using the structure of apoCsCE and ligand-bound RmCE (PDB ID 3WKH, 3WKG) as a search model. Rotation and translation functions were calculated using data of $30.0-1.67-\AA$ resolution. Superimposition of ligand-bound RmCE and CsCE was also optimized by PyMOL by manual fitting. The root mean square deviation (RMSD) values of resulting structures were calculated for all atoms of the protein backbone for the ligand-bound CsCE structure, in order to characterize the amount by which a given selection of predicted molecules deviates from a defined position in space. NAMD 2.6 (http://www.ks.uiuc.edu/Research/ namd/) input files for RMSD analysis were prepared with the VMD program (http://www.ks.uiuc.edu/Research/ 
vmd/). The VMD program was also used for viewing the simulation results. The NAMD output files from minimization and equilibration of ligand-bound $\mathrm{CsCE}$ in a water sphere were used in order to calculate RMSD values and to analyze the extent of equilibration of the simulation. The refined model was simulated in an explicit water environment for $420 \mathrm{ps}$ in an effort to refine the structure and to establish the stability of the model in general. The time history for the RMSD reached a maximum deviation of approximately $1.5 \AA$ after 40 ps, which suggested that the system had converged to a stable structure, or at least a stable local minimum close to the starting structure.

\section{Results}

\section{Selection of target residues for modifying binding properties}

The sequence determined for $\mathrm{CsCE}$ obtained from $C$. saccharolyticus revealed that this $C E$ gene was substantially different from that of other species and contained a 1173-bp ORF encoding 390 amino acids. Sequence alignment with known cellobiose epimerases revealed that all the enzymes have $12 \alpha$-helices, collectively termed the barrel $\left(\alpha_{6} / \alpha_{6}\right)$ [20]. Their structures are quite similar to each other. The $\mathrm{CsCE}$ amino acid sequence shares $45 \%$ identity with $\mathrm{RaCE}$ and $38 \%$ with $\mathrm{RmCE}$, but the structure of CsCE (4Z4L) shares conserved barrel $\left(\alpha_{6} / \alpha_{6}\right)$ domains for cellobiose epimerization activities with all other CE family. Using the apo form of the $\mathrm{CsCE}$ structure, we used substrate binding simulations to model interactions with lactose, based on the structures of RmCE with ligands (3WKG) and RaCE (3VW5) (Fig. 1). As shown in Fig. 1, two essential histidine residues was located in the vicinity of the substrate binding site. Epimerization catalyzed by $\mathrm{CE}$ is likely to proceed with this pair of histidine residues, $\mathrm{H} 377$ and $\mathrm{H} 247$, which gives rise to a converting the configuration of $\mathrm{C} 2$ atom by abstracting and accepting a proton, according to the structural study for the epimerization mechanism of RmCE by Fujiwara et al. [20]. In addition to essential residues related to hydrolysis, there are residues thought to stabilize binding substrate or product. In Fig. 1B, the structure of the active site revealed that Y114 and N184 of $\mathrm{CsCE}$ are located at the interface of the mannose moiety of epilactose in the enzyme-product complex, and are thus easily able to interact with the hydroxyl group in the $\mathrm{C} 2$ position of mannose via $\mathrm{H}$ bonds. $\mathrm{Y} 114$ and N184 residues were observed to be involved in substrate binding but not directly in the lactose epimerization reaction. These residues (Y114 and N184) were considered to play a role in stabilizing the conversion of epilactose. Based on these observations, we hypothesized that the isomerizing byproduct (lactulose) can be produced at increased levels by endowing steric hindrance to the $\mathrm{H}$-bonding of these residues with epilactose, a product of the epimerization reaction. If the enzyme binding sites for the reaction product (epilactose) were distorted by amino acid replacement without inhibiting substrate (lactose) binding, then the isomerizing byproduct, lactulose, can be

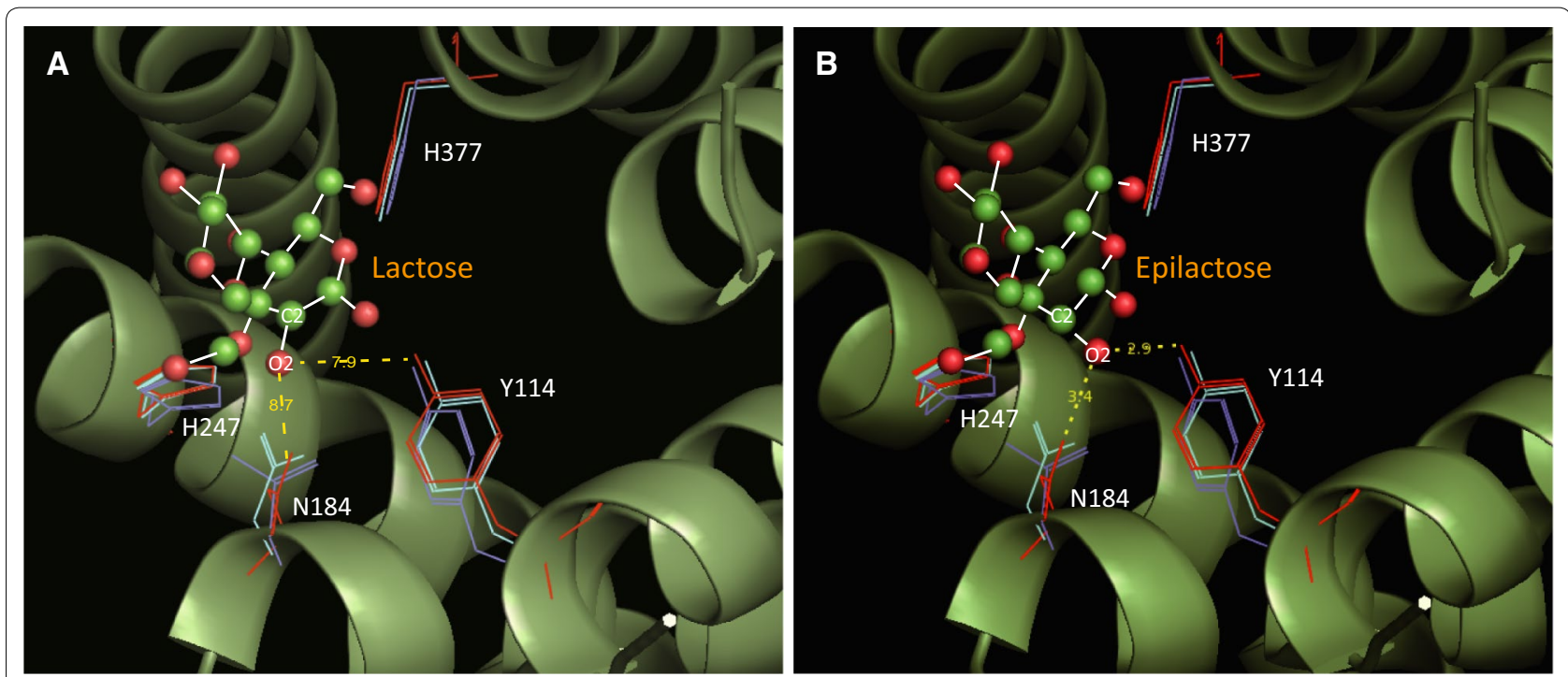

Fig. 1 Superimposition of CsCE onto the RmCE-epilactose (lactose) complex based on the atoms of the 4 conserved active site residues. Based on this model of the binding site structure, the residues that are involved directly in the epimerization of the glucose moiety (His247 and His 377 ) were observed to be highly conserved in the CE and AGE family. Additionally, Tyr114 and Asn184 were proposed to play a role in stabilizing the product and were observed to be closely associated with the stability of the enzyme-lactose/lactulose intermediate complex. A enzyme-lactose complex, B enzyme-epilactose complex 
released through cis-enediol intermediate, instead of completely proceeding through epimerization of lactose to epilactose.

\section{Mutagenesis of $\mathrm{Y} 114$ and N184 in CsCE}

In order to test our hypothesis, the critical residues only involved in product stabilization, Y114 and N184, were targeted for site-directed mutagenesis studies. Y114 and $\mathrm{N} 184$ are well conserved in other enzymes in the cellobiose epimerase family. First, we prepared Y114X clones that covered all amino acid substitutions. All variants were expressed in soluble form and purified by heat treatment and were $>90 \%$ pure as judged by SDS-PAGE analysis (Fig. 2).

Our objective was to identify mutant enzymes that improved lactulose productivity by inhibiting epilactose conversion, while retaining affinity towards lactose. Thus, we investigated the isomerization activity from lactose to lactulose using the Y114X variants. Compared to the parental enzyme, most variants exhibited decreased isomerization activity from lactose to lactulose. The parental enzyme showed high epimerization activity toward epilactose at $37{ }^{\circ} \mathrm{C}$ (Table 1). Interestingly, even though most of Y114X mutants were found to lose activity entirely, the parental enzyme and the Y114E mutant enzyme showed increased isomerization activity from lactose to lactulose at $65{ }^{\circ} \mathrm{C}$ (Table 1 ). This was not surprising as recently CEs were used in the production of lactulose from lactose at higher temperature $\left(60-70{ }^{\circ} \mathrm{C}\right)$ to enhance lactulose yield $[3,13]$. Y114E, however, showed higher isomerization activity while producing less epilactose, compared to parental enzyme at $65{ }^{\circ} \mathrm{C}$. As hypothesized, this result indicated that the formation of epimers through a cis-enediol intermediate to epilactose was inhibited by the adjacent mutated amino acid (Y114E), thereby promoting the release of lactulose as byproduct at $65{ }^{\circ} \mathrm{C}$. At temperatures over
$60{ }^{\circ} \mathrm{C}$, compared to $37^{\circ} \mathrm{C}$, the isomeric byproduct lactulose could be released more readily due to the unstable substrate/product binding caused from an accelerated reaction rate. In addition to the Y114 mutation, we also investigated the conversion activity using an N184X library. All variants showed quite low conversion activity from lactose to lactulose as well as epilactose at both 37 and $65{ }^{\circ} \mathrm{C}$ (Additional file 1: Table S2). This may be due to more severe steric hindrance or charge repulsion compared to the Y114 position.

\section{Release of lactulose by incomplete epimerization}

Substitution of Y114 with glutamate shifted product from epilactose to lactulose instead of completely abolishing the epimerization activity. The lactose conversion assay revealed that the rate of lactose consumption was considerably reduced at $37^{\circ} \mathrm{C}$ but retained at $65^{\circ} \mathrm{C}$ (Fig. 3A). As shown in Fig. 3A, the conversion of lactose into lactulose was temperature dependent and the activity of both enzymes was largely lost at $75^{\circ} \mathrm{C}$. The Y114E mutation significantly reduced epilactose production over the entire range, while the lactulose yield increased with increasing temperature. Interestingly, the isomerization reaction was observed only at high temperatures and more reliably as the substrate increased. Within the range tested for Y114E, lactulose production positively correlated with the lactulose concentration in the reaction mixture. This result indicated that the isomerization ratio of lactulose production was maintained with increasing lactose concentration, while the isomerization ratio of lactulose was decreased in the parental enzyme (Fig. 3B). Taken together, these results indicated that the increased reaction rate induced by high temperature may accelerate a release of the isomeric byproduct (lactulose), leading to maintenance of the isomerization ratio even at high concentrations of substrate (lactose). This finding is consistent with the structural analysis, as mentioned above.

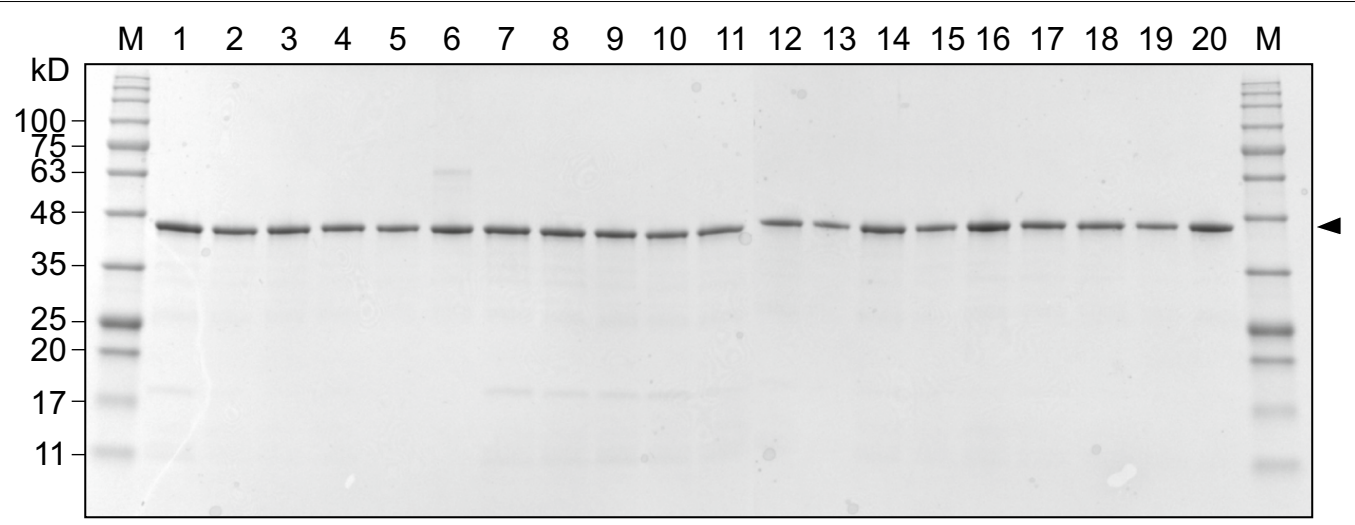

Fig. 2 SDS-PAGE analysis of CSCE variants purified by Ni-affinity chromatography with heat-treated proteins 
Table 1 Comparison of isomerase/epimerase activities on CsCE Y114X mutants at 37 and $65^{\circ} \mathrm{C}$

\begin{tabular}{|c|c|c|c|c|}
\hline \multirow{2}{*}{$\begin{array}{l}\text { Amino acid substituted } \\
\text { in } Y 114\end{array}$} & \multicolumn{2}{|l|}{$37^{\circ} \mathrm{C}$} & \multicolumn{2}{|l|}{$65^{\circ} \mathrm{C}^{\mathrm{a}}$} \\
\hline & $\begin{array}{l}\text { Isomerase activity (mM/ } \\
\min \mu \mathrm{g})\end{array}$ & $\begin{array}{l}\text { Epimerase activity (mM/ } \\
\min \mu \mathrm{g})\end{array}$ & $\begin{array}{l}\text { Isomerase activity (mM/ } \\
\min \mu \mathrm{g} \text { ) }\end{array}$ & $\begin{array}{l}\text { Epimerase activity (mM/ } \\
\min \mu \mathrm{g})\end{array}$ \\
\hline Y (parent) & $15.6 \pm 1.2$ & $138 \pm 2.3$ & $187 \pm 4.2$ & $37.0 \pm 3.6$ \\
\hline V & $9.74 \pm 1.4$ & nd & $29.2 \pm 3.3$ & nd \\
\hline $\mathrm{N}$ & $5.84 \pm 0.71$ & nd & $9.73 \pm 2.2$ & nd \\
\hline S & $1.95 \pm 0.39$ & nd & $17.5 \pm 4.0$ & nd \\
\hline A & $9.74 \pm 2.0$ & nd & $25.3 \pm 3.2$ & nd \\
\hline K & $9.74 \pm 0.98$ & nd & $15.6 \pm 2.1$ & nd \\
\hline G & $3.90 \pm 1.3$ & nd & $15.6 \pm 2.2$ & nd \\
\hline D & $11.7 \pm 1.9$ & nd & $17.5 \pm 2.1$ & nd \\
\hline C & $5.84 \pm 1.0$ & nd & $15.6 \pm 1.9$ & nd \\
\hline L & nd & nd & $29.2 \pm 2.6$ & nd \\
\hline$E$ & $17.5 \pm 2.3$ & nd & $208 \pm 3.9$ & $11.7 \pm 2.2$ \\
\hline P & $1.95 \pm 0.55$ & nd & $17.5 \pm 1.2$ & nd \\
\hline I & $7.79 \pm 1.9$ & nd & $17.5 \pm 1.1$ & nd \\
\hline W & nd & nd & $11.7 \pm 1.2$ & nd \\
\hline T & $3.90 \pm 0.2$ & nd & $7.81 \pm 2.1$ & nd \\
\hline R & nd & nd & $13.6 \pm 1.0$ & nd \\
\hline $\mathrm{F}$ & $1.95 \pm 0.13$ & $9.74 \pm 2.1$ & $48.7 \pm 3.2$ & $9.77 \pm 3.2$ \\
\hline M & $3.90 \pm 0.22$ & nd & $17.5 \pm 2.9$ & nd \\
\hline Q & $1.92 \pm 0.08$ & nd & $23.4 \pm 3.4$ & nd \\
\hline $\mathrm{H}$ & nd & nd & $15.6 \pm 2.8$ & nd \\
\hline
\end{tabular}

Isomerase and epimerase activities were measured by quantifying lactulose and epilactose which were converted from $20 \mathrm{~g} / \mathrm{l}$ lactose for $30 \mathrm{~min}$ at testing temperature. Values are mean \pm SD measured from three experimental replicates

nd, not detected

a Under this condition, lactulose formed by non-enzymatic isomerization was negligible

\section{Production of lactulose using Y114E mutant enzyme}

To evaluate our Y114E enzyme, we tested lactulose production with the parental and Y114E enzymes under the condition described by $\mathrm{Oh}$ et al. [3, 13]. When $200 \mathrm{~g} / \mathrm{l}$ of lactose was subjected to substrate under the reported conditions, Y114E produced $86.9 \mathrm{~g} / \mathrm{l}$ of lactulose and $4.6 \mathrm{~g} / \mathrm{l}$ of epilactose, while the parental enzyme produced $61.2 \mathrm{~g} / \mathrm{l}$ of lactulose and $24.6 \mathrm{~g} / \mathrm{l}$ of epilactose (Fig. 4). The isomerization of lactose no longer proceeded after $2 \mathrm{~h}$, leading to an equilibrium state, whereby the ratio (lactose:lactulose:epilactose) in reaction mixtures containing the parental and Y114 enzyme were 57:31:12 and 53:45:2, respectively. These results showed that isomerization of lactose was increased by the Y114E mutation, while epimerization of lactose was decreased. Although RmCE have high activities of both epimerization and isomerization at mesophilic temperature, the relationship between its isomerization activity and the phyla of the originating organism was reported to be unclear [25]. However, at least in high substrate condition (over $100 \mathrm{~g} / \mathrm{l})$, most of CEs showed an increased isomerization activity than epimerization activity at high temperature. In this study, the subtle modification of the active pocket to inhibit stable binding to the end product (epilactose), could extend its activity from epimerization to isomerization without significantly impairing substrate binding at high temperature, thereby demonstrating the potential of an approach based on structure analysis for targeted mutagenesis of $\mathrm{CE}$ to alter its biocatalytic reaction to accumulate a desired product.

\section{Discussion}

In this study, we applied structural analysis to enzyme active site pocket engineering for lactulose production. Specifically, end product stabilizing residues were replaced by amino acids that can inhibit product binding to increase production of lactulose, the isomeric byproduct of the epimerization reaction, at $65{ }^{\circ} \mathrm{C}$, while the native epimeric product of the reaction, epilactose, was reduced. Generally, engineering active pocket residues is known to be difficult to change activity, because these residues play important roles in the reaction process. Likewise, in our case, combinations of Y114E along with active site residue N184, identified as another possible candidate in our structural analysis, did not show desirable results (Additional file 1: Table S3). 

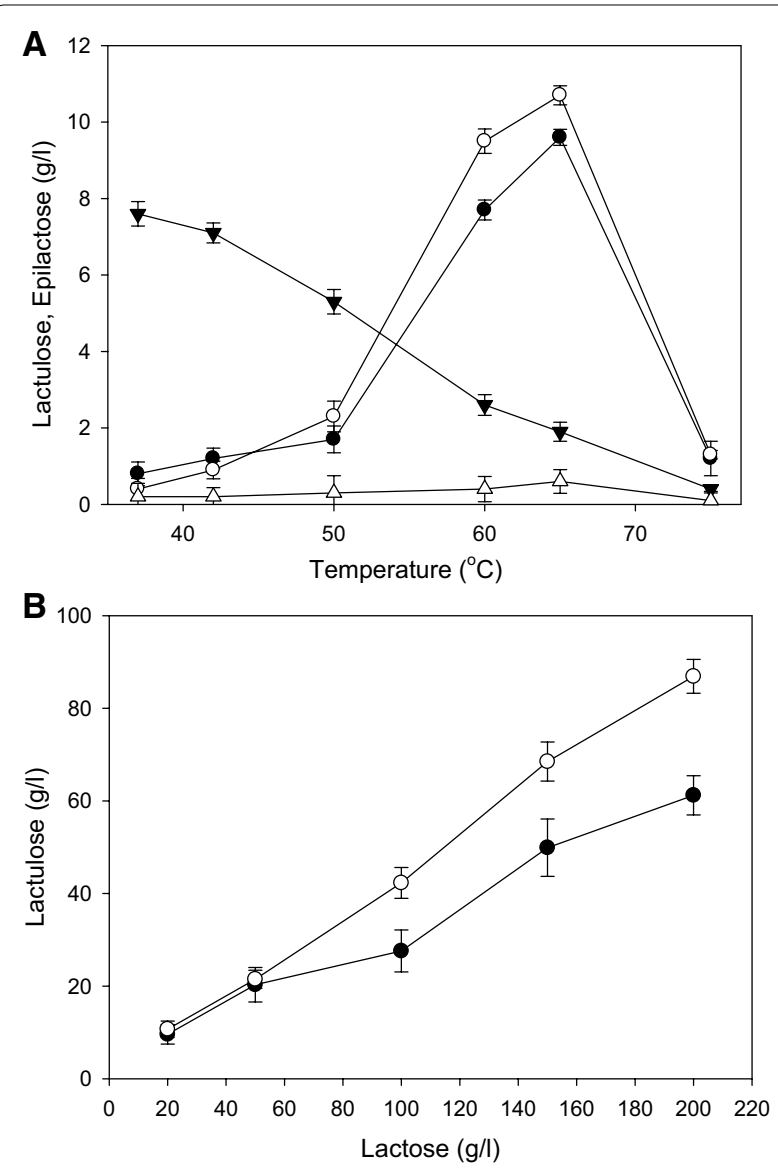

Fig. 3 Effects of temperature and lactose concentration on activity using parental and Y114E enzymes. Lactulose (parental enzyme) (0) lactulose (Y114E enzyme) (O), epilactose (parental enzyme) $(\boldsymbol{\nabla})$ and epilactose (Y114E enzyme) ( $\triangle$ ). A Effect of reaction temperature.

Each $50 \mu \mathrm{g}$ of enzyme was incubated with $20 \mathrm{~g} / \mathrm{l}$ substrate solution at the range of $37-75^{\circ} \mathrm{C}$ for $2 \mathrm{~h}$. B Effect of lactose concentration. Each $50 \mu \mathrm{g}$ of enzyme was incubated with $20-200 \mathrm{~g} / \mathrm{l}$ substrate solution at $65^{\circ} \mathrm{C}$ for $2 \mathrm{~h}$

The replacement of Y114 by glutamate appears to involve an interesting environmental change whereby inhibiting the interaction between Y114 and the hydroxyl group in the $\mathrm{C} 2$ position of the mannose moiety prevents an epimerization of cis-enediol intermediate [12, $19,20,23]$. The fact that prevention from interacting with the end product is necessary but not sufficient for lactulose production suggests the involvement of external environment conditions, such as high substrate concentration and high temperature that help to induce unstable epimerization or epilactose conversion by accelerating the reaction rate. Indeed, screening of heat resistant enzymes for lactulose production has been pursued by many researchers, including cell- or
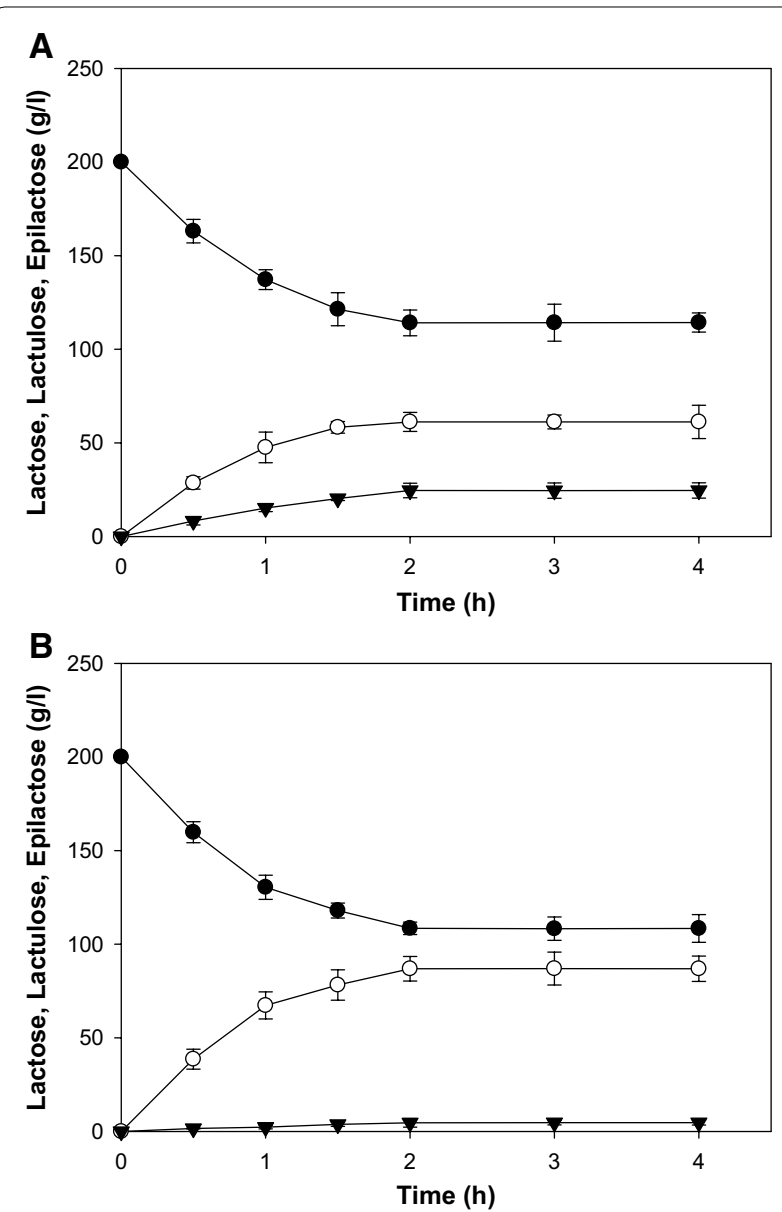

Fig. 4 Conversion of lactose into lactulose in batch reaction using parental (A) and Y114E enzymes (B). Each enzyme was incubated with $200 \mathrm{~g} / \mathrm{l}$ of substrate solution at $65^{\circ} \mathrm{C}$ for $4 \mathrm{~h}$. Lactose $(\mathbf{O})$, lactulose $(O)$, epilactose $(\boldsymbol{V})$

enzyme-immobilization reactors which are applicable for industrial use [4, 14, 15, 26-28].

Recently, Fujiwara et al. proposed epimerization mechanism in RmCE. In this proposed mechanism, His390 (corresponding to His377 in CsCE) is served as an acid/ base catalyst for ring opening/closure by donating a proton to the $\mathrm{O} 5$ atom of the reducing end moiety of the substrate and abstracting the proton from the $\mathrm{O} 1$ atom of the same moiety, respectively [20]. In the direction of Glc to Man, initially deprotonated His390 of RmCE abstracts the proton from the $\mathrm{O} 1$ atom of the reducing end $\mathrm{D}$-glucose residue, and then the resulting $\mathrm{O} 5$ anion accepts a proton from the protonated His390, in agreement with the following role of His390 as the base catalyst to form the cis-enediol intermediate. The mechanism of ring closure can be interpreted as the inverse reaction of ring 
opening. After the protonation/reprotonation step, rotation about the $\mathrm{C} 2-\mathrm{C} 3$ bond may occur again and position the $\mathrm{O} 1$ atom of the reducing end moiety of the substrate close to the $\mathrm{O} 5$ atom of the same moiety. Then, the electron pair on the $\mathrm{O} 5$ anion caused by deprotonation with His390 attacks the electron-deficient $\mathrm{C} 1$ atom to remake the $\mathrm{C} 1-\mathrm{O} 5$ bond [20]. Based on the proposed mechanism by Fujisawa, as an increase of $\mathrm{pH}$ by shifting temperature may affect to the role of His390 as acid/base, epimerization of lactose can be reduced by incubation at high temperature. Additionally, it is quite reasonable that the function of His390 acting on cis-enediol intermediate may be changed by replacing residues near active pocket. Taken together, it can be a possible explanation that His247 of CsCE, corresponding to His 259 of RmCE, may transfer $\mathrm{H} 2$ to $\mathrm{C} 1$ rather than $\mathrm{C} 2$ of the cis-enediol intermediate by subtle environmental change of $\mathrm{Y} 114 \mathrm{E}$ substitution, leading to an increase of isomerization/ epimerization ratio under our incubation condition at high temperature [25].

$\mathrm{CsCE}$, used as parent enzyme in this study, is known to convert aldose substrates with hydroxyl groups in the right-hand configuration at the $\mathrm{C} 2$ position to their epimers with the C2 hydroxyl groups in the left-hand configuration, while retaining left-hand configuration at the C3 position during epimerization [12]. Additionally, $\mathrm{CsCE}$ is known to have isomerization activity for both aldoses monosaccharides and cellobiose with up-shifting reaction parameters, i.e. enzyme amounts, incubation time and temperature, while CE from E. cellulosolvens, $R$. albus, and $B$. fragilis had no activity for monosaccharides and exhibited much higher epimerization activity for cellobiose than isomerization $[18,29,30]$. While not investigated in this study, we presume that RaCE may have a more rigid structure than $\mathrm{CsCE}$, because $\mathrm{RaCE}$ is more thermostable than CsCE $[19,21]$. This would explain how thermostable RaCE exhibits more specific epimerization activity than CsCE. Even though the relationship between thermostability and epimerization activity is not clearly explained, $\mathrm{CsCE}$ could be a much better candidate for this engineering compared to $\mathrm{RaCE}$ for this reason.

From a technological standpoint, a notable outcome of the studies described here was support of a hypothesis derived from structural analysis by engineering targeted active site residues for enhancing lactulose production. We demonstrated that interaction of the enzyme with product was inhibited by replacing Y114 with glutamate, leading to the release of lactulose. In particular, we showed increased lactulose production from lactose in Y114E compared to the parental enzyme at high temperature $\left(65^{\circ} \mathrm{C}\right)$ and high substrate concentration, while Y114E seemed to almost lose both epimerization and isomerization activity at $37{ }^{\circ} \mathrm{C}$. Notably, the engineering described here has the potential to improve the enzyme activity and enlarge its industrial application.

\section{Additional file}

Additional file 1. Figure S1. Three-dimentional structure of CSCE (PDB ID: 4Z4L). Table S1. Data and refinement statistics. Table S2. Comparison of isomerase/epimerase activities on CSCE N184X mutants at $37^{\circ} \mathrm{C}$ and $65^{\circ} \mathrm{C}$. Table S3. Comparison of isomerase/epimerase activities on N184Q, N184D and N184R mutants combined with $\mathrm{Y} 114 \mathrm{E}$ at $65^{\circ} \mathrm{C}$.

\section{Abbreviations}

CE: cellobiose 2-epimerases; CsCE: Caldicellulosiruptor saccharolyticus CE; RaCE: Ruminococcus albus CE; RmCE: Rhodothermus marinus CE; AGE: N-acetylglucosamine 2-epimerase.

\section{Authors' contributions}

AP and JK performed research, analyzed data, and wrote the paper. SJ and YP analyzed data. BK designed research, reviewed data. HL conceptualized project, designed research, analyzed data, and wrote the paper. All authors read and approved the final manuscript.

\section{Acknowledgements}

This work was carried out with the support of "Cooperative Research Program for Agriculture Science \& Technology Development (Project No. PJ01224202)" Rural Development Administration, Republic of Korea.

\section{Competing interests}

The authors declare that they have no competing interests.

Availability of data and materials

Not applicable.

Consent for publication

Not applicable.

Ethics approval and consent to participate Not applicable.

Funding

Rural Development Administration, Republic of Korea. Award Number PJ01224202, Recipient: Bong-Seong Koo.

\section{Publisher's Note}

Springer Nature remains neutral with regard to jurisdictional claims in published maps and institutional affiliations.

Received: 19 September 2017 Accepted: 6 December 2017

Published online: 12 December 2017

\section{References}

1. Hua X, Yang R, Shen Q, Ye F, Zhang W, Zhao W. Production of 1-lactulose and lactulose using commercial $\beta$-galactosidase from Kluyveromyces lactis in the presence of fructose. Food Chem. 2013;137:1-7.

2. Khatami S, Ashtiani FZ, Bonakdarpour B, Mehrdad M. The enzymatic production of lactulose via transglycosylation in conventional and nonconventional media. Int Dairy J. 2014;34:74-9.

3. Kim YS, Oh DK. Lactulose production from lactose as a single substrate by a thermostable cellobiose 2-epimerase from Caldicellulosiruptor saccharolyticus. Bioresour Technol. 2012;104:668-72.

4. Mayer J, Kranz B, Fischer L. Continuous production of lactulose by immobilized thermostable $\beta$-glycosidase from Pyrococcus furiosus. J Biotechnol. 2010;145:387-93. 
5. Aït-Aissa A, Aïder M. Lactulose: production and use in functional food, medical and pharmaceutical applications. Practical and critical review. Int J Food Sci Technol. 2014;49:1245-53.

6. Corzo N, Alonso JL, Azpiroz F, Calvo MA, Cirici M, Leis R, Lombo F, MateosAparicio I, Plou FJ, Ruas-Madiedo P, et al. Prebiotics: concept, properties and beneficial effects. Nutr Hosp. 2015;31(Suppl 1):99-118.

7. Watanabe J, Nishimukai M, Taguchi H, Senoura T, Hamada S, Matsui H, Yamamoto T, Wasaki J, Hara H, Ito S. Prebiotic properties of epilactose. J Dairy Sci. 2008;91:4518-26.

8. Aider $M$, de Halleux D. Isomerization of lactose and lactulose production: review. Trends Food Sci Technol. 2007;18:356-64.

9. Panesar PS, Kumari S. Lactulose: production, purification and potential applications. Biotechnol Adv. 2011;29:940-8.

10. Sitanggang $A B$, Drews $A$, Kraume M. Continuous synthesis of lactulose in an enzymatic membrane reactor reduces lactulose secondary hydrolysis. Bioresour Technol. 2014;167:108-15.

11. Sitanggang AB, Drews A, Kraume M. Development of a continuous membrane reactor process for enzyme-catalyzed lactulose synthesis. Biochem Eng J. 2016;109:65-80.

12. Park CS, Kim JE, Choi JG, Oh DK. Characterization of a recombinant cellobiose 2-epimerase from Caldicellulosiruptor saccharolyticus and its application in the production of mannose from glucose. Appl Microbiol Biotechnol. 2011;92:1187-96.

13. Shen Q, Zhang Y, Yang R, Pan S, Dong J, Fan Y, Han L. Enhancement of isomerization activity and lactulose production of cellobiose 2-epimerase from Caldicellulosiruptor saccharolyticus. Food Chem. 2016;207:60-7.

14. Park A-R, Koo B-S, Kim J-S, Kim E-J, Lee H-C. Lactulose production using immobilized cells including thermostable cellobiose 2-epimerase. Microbiol Biotechnol Lett. 2016:44:504-11.

15. Song YS, Suh YJ, Park C, Kim SW. Improvement of lactulose synthesis through optimization of reaction conditions with immobilized ß-galactosidase. Korean J Chem Eng. 2013;30:160-5.

16. Wang H, Yang R, Hua X, Zhao W, Zhang W. Enzymatic production of lactulose and 1-lactulose: current state and perspectives. Appl Microbiol Biotechnol. 2013;97:6167-80.

17. Tyler T, Leatherwood J. Epimerization of disaccharides by enzyme preparations from Ruminococcus albus. Arch Biochem Biophys. 1967;1 19:363-7.

18. Ito S, Hamada S, Yamaguchi K, Umene S, Ito H, Matsui H, Ozawa T, Taguchi $\mathrm{H}$, Watanabe J, Wasaki J, Ito S. Cloning and sequencing of the cellobiose 2-epimerase gene from an obligatory anaerobe, Ruminococcus albus. Biochem Biophys Res Commun. 2007;360:640-5.

19. Fujiwara T, Saburi W, Inoue S, Mori H, Matsui H, Tanaka I, Yao M. Crystal structure of Ruminococcus albus cellobiose 2-epimerase: structural insights into epimerization of unmodified sugar. FEBS Lett. 2013;587:840-6.

20. Fujiwara T, Saburi W, Matsui H, Mori H, Yao M. Structural insights into the epimerization of beta-1,4-linked oligosaccharides catalyzed by cellobiose 2-epimerase, the sole enzyme epimerizing non-anomeric hydroxyl groups of unmodified sugars. J Biol Chem. 2014;289:3405-15.

21. Ito S, Hamada S, Ito H, Matsui H, Ozawa T, Taguchi H, Ito S. Site-directed mutagenesis of possible catalytic residues of cellobiose 2-epimerase from Ruminococcus albus. Biotechnol Lett. 2009;31:1065-71.

22. Lee YC, Wu HM, Chang YN, Wang WC, Hsu WH. The central cavity from the (alpha/alpha)6 barrel structure of Anabaena sp. CH1 N-acetyl-D-glucosamine 2-epimerase contains two key histidine residues for reversible conversion. J Mol Biol. 2007;367:895-908.

23. Ojima T, Saburi W, Sato H, Yamamoto T, Mori H, Matsui H. Biochemical characterization of a thermophilic cellobiose 2-epimerase from a thermohalophilic bacterium, Rhodothermus marinus JCM9785. Biosci Biotechnol Biochem. 2011;75:2162-8.

24. Adams PD, Afonine PV, Bunkoczi G, Chen VB, Davis IW, Echols N, Headd JJ, Hung LW, Kapral GJ, Grosse-Kunstleve RW, et al. PHENIX: a comprehensive Python-based system for macromolecular structure solution. Acta Crystallogr D Biol Crystallogr. 2010;66:213-21.

25. Kuschel B, Seitl I, Gluck C, Mu W, Jiang B, Stressler T, Fischer L. Hidden reaction: mesophilic cellobiose 2-epimerases produce lactulose. J Agric Food Chem. 2017:65:2530-9.

26. Kim Y, Koo BS, Lee HC, Yoon Y. Improved production of isomaltulose by a newly isolated mutant of Serratia sp. cells immobilized in calcium alginate. Can J Microbiol. 2015;61:193-9.

27. Song YS, Lee HU, Park C, Kim SW. Batch and continuous synthesis of lactulose from whey lactose by immobilized $\beta$-galactosidase. Food Chem. 2013;136:689-94.

28. Sato H, Saburi W, Ojima T, Taguchi H, Mori H, Matsui H. Immobilization of a thermostable cellobiose 2-epimerase from Rhodothermus marinus JCM9785 and continuous production of epilactose. Biosci Biotechnol Biochem. 2012;76:1584-7.

29. Senoura T, Taguchi H, Ito S, Hamada S, Matsui H, Fukiya S, Yokota A, Watanabe J, Wasaki J, Ito S. Identification of the cellobiose 2-epimerase gene in the genome of Bacteroides fragilis NCTC 9343. Biosci Biotechnol Biochem. 2009;73:400-6.

30. Taguchi H, Senoura T, Hamada S, Matsui H, Kobayashi Y, Watanabe J, Wasaki J, Ito S. Cloning and sequencing of the gene for cellobiose 2-epimerase from a ruminal strain of Eubacterium cellulosolvens. FEMS Microbiol Lett. 2008:287:34-40.

\section{Submit your next manuscript to BioMed Central and we will help you at every step:}

- We accept pre-submission inquiries

- Our selector tool helps you to find the most relevant journal

- We provide round the clock customer support

- Convenient online submission

- Thorough peer review

- Inclusion in PubMed and all major indexing services

- Maximum visibility for your research

Submit your manuscript at www.biomedcentral com/submit
BioMed Central 